\title{
The Current Situation of Public Safety Incidents and Its Cause
}

\author{
Zhao Xiuhua \\ School of Marxism Studies, Renmin University of China. Beijing, P.R.China, 100872
}

(Email: Zhaoxh8536@163.com)

\begin{abstract}
The study of the current situation of our country and its cause is necessary to cut back public safety problems. According to the national situation, the cause of public safety's hidden danger can be considered from the following five perspectives: Natural causes, Economic factors, Political factors, Technological factors and Cultural awareness factors. These five aspects interact, and together frame the reasons of public safety issues in China. In this paper, I combine research methods of observation and literature review. The innovation of this paper is to make the classification of the public safety problems problemsproblems cause, and make the incentives analysis with a full detail.
\end{abstract}

KeyWords: Public safety, incidents, current situation, cause

\section{Introduction}

Based on the existing information collection of public safety, books dedicated to public safety research are rare. However, the paper has a huge number. Especially with the increasing number of public events in recent years, the number grows bigger and bigger. A series of research papers on the importance of public safety, deficiencies and problems in the management of public safety and public safety system. Things should be noted that, Most of the focus of the study of these papers is on one aspect of public safety issues or aspects or different emphasis. Thorough, in-depth research paper on public safety issues is few. Moreover, most of these papers is studying the country's public security issues, while involve very few such problems abroad. Only a handful of articles involve foreign public security-related issues, and the work of comparison and reference is not enough. As for the concept of "public safety", different scholars give different interpretations from different angles. For example, Xiao Yang, from the Law point of view, pointed out that, "Public safety is something that intentionally or negligently implements certain behavior which is enough to harm the lives of most people or major private property." Scholars Deng Guoliang think that, Public safety crises of natural disasters, man-made catastrophes and social conflicts caused by social confrontation behavior, which endanger public safety, cause or may cause serious harm to society. Some scholars believe that the public safety has a narrow and broad sense. Other scholars believe that, public safety issue is the scope of public goods, something that offered by government with public power. It is obvious that, the view above understand public safety from different perspective. But this often limits to a certain point of view and makes problem fragmented, can not show us the overall public safety problems and their severity. As Wang Yanji from Renmin University of China said that, with the opening up and development of the society, public safety's constituent elements and mechanism of action tends to be complex. Its connotation and extension will continue to expand, and it is undergoing a change from quantity to quality. The existing research focuses on the following aspects:

First of all, the study focused on the classification and features of. According to the public time, the nature and mechanism, they divide public safety as natural disasters, accidents, public health emergencies, and social security events, the four major categories. This classification is rather scientific overall, but it should be based on the times required to focus and highlight, such as, 
economic crisis, a serious lack of resources, energy and the necessities of life, the financial credit crisis and so on.

Secondly, scholars have different focus on the reason of public safety. For example, Professor Wu Aiming summarized them as: world-wide terror activities, a wide range of infectious diseases, frequent occurrence of natural disasters, sudden major personal casualties and the harm caused by the poor of the illegal production and shoddy products. Scholars Lin Xiongdi put it summed up the natural, political, economic, cultural awareness and ethnic and religious five aspects. All these analysis is reasonable to some extent, but the defect is lack of uniform sstandards and focus. But paid insufficient attention to the impact of globalization for public safety. Involve a relatively few individuals for the event to vent their anger on social discontent, economic security events and foreign-related incident. But the fact is that these factors are precisely the important factors that public safety can not be ignored.

Thirdly, scholars have different views of countermeasures. Wang Yan scholars have pointed out that, development of social and public security system should be in line with our community policing, and give play to the functions of public and social organizations, re-integrate the elements of public safety, and build a government management and public participation in the combination of social and mercerization of public security system. It should be acknowledged that the relevance of these recommendations are very strong and of great practical significance, but they are either too general, or just about a specific aspect of some of the most important countermeasures, they lack maneuverability. In fact, the public safety system is a complex engineering; It needs a comprehensive plan as well as specific and feasible measures, which are closely linked with its causes. Therefore, this article focuses on the analysis of the reasons of public safety issues.

In the light of international data, the period when the capita GDP is between $\$ 1000$ and $\$ 3000$ is high incidence of public safety incidents." ${ }^{[1]}$ Our country is into this phase when new concepts collides old ones and social structure changes. All these lead to Imbalance in distribution, moral losing its exemplary role and society being in an unstable state. The outbreak of SARS in 2003 , the stampede of Miyun Beijing in 2004, the frequent occurrence of Coal Mine Safety events, the milk powder incident of Anhui Fuyang, Wenchuan Earthquake of 2008, all these are big endangering Public safety incidents. Modern Risks and threats are rising while traditional security threats still. Public safety issue has become a serious obstacle to building a socialist harmonious society in China.

It is worth pondering that this situation has not being attached importance. The protecting base is relatively weak and out of the pace of economic development. These constraints the comprehensive, coordinated and sustainable development of national economy, On the other hand, "with the development of economic and social, people's expectations of the masses of security is increasing. How to minimize security incidents and the resulting loss has become a prominent issue to build a harmonious socialist society.”[2]

\section{Cause Analysis}

\subsection{Natural Causes}

It is an important factor in public safety incidents that natural disasters are difficult to safeguard. China is a natural disaster-prone country. The data indicates that more than a dozen cities in our country are facing one or more kinds of threat form natural disasters. China has more earthquakes than other countries, which are frequent, magnitude, and widely distributed. Since 1998, occurred 8 earthquakes above 7 magnitude and more than 40 earthquakes above 6magnitude. Statistics show that, meteorological disasters has brought 2114600000000 direct economic losses to China's national economy the between 1993 and 2003. In 1991, catastrophic floods caused severe urban loss. 22 cities in Jiangsu province suffered disaster, nearly 30,000 enterprises stopped or half cut and 6,170,000 houses collapsed. [3] Moreover, Greenhouse effect and El Niño Phenomenon caused by air pollution and environmental degradation will be a growing threat to human life and property safety. The increasing difficulty in withstanding natural disasters must be attached great importance. 


\subsection{Economic Factors}

Disharmony in economy is the root cause of the induced public safety incidents. Observed from the international statistics, public safety incidents will increase when per capita GDP is in $1000-\$ 3000$. [4] During this period, the economy has entered a stage of rapid development while unstable social factors increase. At the same time, China's development gap between urban and rural areas is widening in this period, in 2000 , the per capita income of eastern part was 2.26 times that of the western ones. The gap between the highest province and the lowest provincial is more above three times, and the averages masked the actual difference. Actually, our income Gina coefficient has been above 0.50 , much higher than the usual social stability cordon 0.40 . [5] Too large gap in income distribution will have a severe impact on people's thoughts, beliefs and value systems, and give threat to social security and stability.

First of all, poverty will aggravate the security risks due to the widening gap between rich and poor. Enormous pressure on family economy is an important reason for the individual security incidents. Maslow's hierarchy of needs theory suggests that people will rarely consider the security needs under the premise of survival are not guaranteed. In most cases, the victims of security incidents are vulnerable groups, the majority of which are forced by the need of livelihood to labor in extremely dangerous circumstances. So this situation is more apparent in safety accidents of production. Now, while the technology is developing at a high rate, the need of labor is relatively reducing. But the number of labor to be in employment on the market is definitely increasing. Competition for jobs is becoming more and much fiercer. To ordinary citizens, especially those migrant workers working in cities, to get a job has been very lucky, not to mention whether the job is safe. To some extent, this makes living space for those facilities which are undocumented, unlicensed. In addition, China has not yet reached the overall well-off, Social Security is still inadequate. Although state and government have been working hard, the survival needs of those vulnerable groups is still superior to security. When minimum survival needs are largely rely on their own safety of life, when some people have no choice except risking life insurance, safety accident rate also have no choice but rise.

Opposed to poverty, sometimes wealth will become a safety hazard. Security incidents occurred in the transportation, tourism is often caused by wealth rather than poverty. Along with the improving of people's material and cultural living standards, people are more interested in public events, travelling and private cars will increase. But they have not developed the good habit of always safety first. Moreover, along with the accelerated process of urbanization and urban modernization, the city's population concentration and concentration of production is rising sharply. This concentration brings us high productivity but also new risks. The city's high-rise buildings and intensiveness of Oil, gas, water, electricity and other critical facilities will cause a chain reaction once some security incident takes place.

\subsection{Political factors}

To some extent, government's inaction exacerbated the severity of the Public Security. The Seventeenth Party Congress proposed to build a service-oriented government. This is because the Government's duty is to provide the community with high - quality public goods and to create a comfortable and safe working environment for people. In accordance with the Public Security Products theory, the safety issue means that Government provides services to citizens with public power, and this is part of the scope of public goods. The frequency of public safety accident illustrates of the intentional or unintentional omission of government. This is mainly manifested in the following two aspects:

In the objective aspect, there are still many loopholes in government management of public safety. Such as, the mechanisms of public safety regulatory are inadequate; there are little good communication among the horizontal regulatory mechanism. Secondly, we still lack a proven crisis response mechanism, the fragmentation of Crisis Management is serious, our crisis management is still in the reactive phase, we still Lack specialized agencies system. Furthermore, incentives and punishment mechanism are of dislocation, performance test system is not perfect and so disadvantages, some government departments will try to cover problems rather than timely response to when 
they encounter a problem. Thirdly, the government's emergency rescue capability is Limited now. We must face this reality that long-term indifference has led to poorly equipped and lack of information construction. According to statistics, the country's safety and emergency rescuing forces are scattered in various departments. The shortage and dispersion of emergency rescuing human resources, coupled with the lack of disaster reduction expertise and disaster prevention knowledge results in slow response of the emergency rescue.

In the subjective aspect, there is government's deliberate omission. It manifests in the following points: first of all, government departments lack sense of responsibility and crisis. Their understanding of new crisis's root is insufficient, so they are still passive in disaster management. Secondly, the collusion between business and officers also contributes to security incidents. Some government officials, driven by the interests, are at the stake of some business and become the umbrella of security incidents. All these result in one-sided pursuit of economic efficiency and large number of potential accidents. Thirdly, the funding for public safety is relatively lack, while the implementation and improvement of public security crisis management mechanism largely depend on it. As far as the city, concentrated to deal with a few unexpected events should be no problem with the current city government's financial ability. However, due to lack of funds source and assurance shortage, the financial constraints have been the "bottleneck" to improve China's public security crisis management mechanism. "Data shows that, between 1997and1998, the average ratio of public health financial expenditure was $1.26 \%$ in low-income countries, while middle-income countries $2.25 \%$, China Only 0.62\%." [6]

\subsection{Technological actors}

We do not have a permanent, authoritative public safety handle coordinating management structure. It is obviously impossible to complete the huge responsibility to protect the country rely on a few departments. But the fact is that we do not have an authoritative coordinating body. In most cases, our anti-disaster system is still sub-sectors. However, a variety of public safety events are with the characteristics of the mass and chain.
Their prevention and solutions often require a multifaceted cooperation. If we have temporary leading teams alone rather than an authoritative coordinating body, resource information can't be effectively integrated in a short time once the complex security problems occur. Our ability to deal with emergencies will be greatly reduced and the prime time of the disaster relief will be ultimately bungled.

Secondly, the allocation of talent is not enough scientific. While we lack professionals, the team of volunteers is inadequate. In recent years, the complexity of the public safety events is significantly enhanced and put forward higher requirements for the quality of personnel." However, most of employer's employment mechanism is still 'able to enter but not leave out', and this lead to the fact that professionals can't get in while the surplus staff can't be wed out. The number of workers is big but the efficiency is not high." [7] At the same time, volunteer team building is not enough. Once the incident occurs, the more high-quality social forces can not be gathered in a short period of time. In addition, due to the Basic Law of disaster prevention is not perfect, we can not ensure the implementation of urban disaster prevention and mitigation planning.

\subsection{Cultural awareness}

Not being psychologically prepared for a serious of emergencies is a kind of incentive to public safety issues. When SARS spred in 2003, many people snapped food in supermarket, and this phenomenon bring about a great deal of waste of resources. The root cause of so negative influence of SARS is shortage of social crisis knowledge. So, strengthening people's sense of crisis is an important aspect can not be ignored.

Secondly, terrorism, ethnic separatism and economic globalization bring new problems to China's public security. The global interdependence is deepening in context of world economic integration. The usage of external resources to develop economy brings new challenges to public safety. As a whole, there are still various contradictions under the theme of peace and development. Such as terrorist attacks, Local war, financial crisis, competition for resources, the spread of transnational major outbreaks and so on, there are more and more non-traditional security issues. A wide range of highly infectious disease, such as AIDS, Mad Cow Disease, 
Dengue fever, SARS and Avian influenza, seriously interfere with the lives of people around the world. Worldwide terrorist forces are on the rise, and the spread is developing. Under the influence of worldwide ethnic conflicts, regional conflicts, religious conflicts and sharp cultural values conflicts, there have been ethnic separatism, terrorism and terrorist activities in some regions of China. The wantonly separatist's activities of East Turkistan and Tibetan separatist's vandalism events on 3.14 of 2008, whose reckless behavior is under the support of the ethnic separatist forces from worldwide. All these constitute a great threat to China's public security.

\section{Conclusions}

Public safety is not an fixed abstract concept, its meaning changing with the historical changes in the environment. Public safety problems can not be accomplished overnight, nor can once and for all. So, we must adhere to the scientific development concept to guide the overall work of public safety, fully estimate the safe development's long-term, arduousness and complexity, strengthen sense of crisis and sense of responsibility. Adhere to the "safety first, comprehensive treatment approach; both do a good job with the emergency, but also focus on $\mathrm{p}$ prevention of accidents; to attach importance to science and technology while also ensure public safety management system and organizational security; establish a public safety incentive and restraint mechanisms to speed up legislation on public safety. Fully mobilize all social forces, unite all can be united, utilize all available resources to minimize the threat to public security.

\section{References}

[1] ZhangQiang, "Discussion of public safety and security-building mechanisms", International Technical and Economic Research, pp. 14 15, 2004.

[2] http://www.gov.cn/wszb/zhibo191/content 855499.htm

[3] Tan Qinglian. "Raise the comprehensive capacity of disaster reduction to protect the city public safety", China Civil Engineering Journal, p.105, 2005.

[4] Yang Ping, and Huang Hua. "Ensure public safety to build a harmonious society", The Nanning Municipal Party School Journal, pp. 26 27, 2005.

[5] Zhu Dunjun, "Causes and countermeasures of the rural public safety risk", Jiangxi Institute of Education (Social Sciences), p.17, 2008.

[6] Pan Jiajun, and Zhang Xiaodan, "Defect and reconstruction of the transition period of China's urban public security system", Social scientists, p. 45, 2004.

[7] Zhang Chuanyou, "Strengthening the management thinking of China's public security", Yangtze Forum, pp. 43 44, 2007. 